\title{
Reconsidering the patient-centeredness of osteopathy
}

\author{
Oliver P. Thomson ${ }^{\mathrm{a}, \mathrm{b}, \mathrm{c}, *}$, Nicola J. Petty ${ }^{\mathrm{a}}$, Ann P. Moore ${ }^{\mathrm{a}}$ \\ ${ }^{a}$ University of Brighton, Clinical Research Centre for Health Professions, Eastbourne, United Kingdom \\ ${ }^{\mathrm{b}}$ The British College of Osteopathic Medicine, Research Department, London, United Kingdom \\ ' Oxford Brookes University, The Department of Sport and Health Sciences, Faculty of Health and Life \\ Sciences, Oxford, United Kingdom
}

\begin{abstract}
The widespread use of the biopsychosocial model amongst various health professions, all of which claim to take a patient-centred approach to their practise, challenges what has been considered a unique and defining feature of osteopathy. This paper discusses the complexity of what is meant by patient-centeredness, and how it is practised and researched by other health professions. The assumption that osteopathy has always taken a patient-centred approach is questioned, and directions for further research are highlighted so that the profession can have a comprehensive working knowledge of its practise, thereby helping to define itself within the broad and competitive healthcare environment.
\end{abstract}

\section{KEYWORDS}

Patient-centeredness; Patient-centred care; Clinical reasoning; Osteopathy; Qualitative;

Evidence-based practise

\section{Introduction}

In many parts of the world, osteopathy is considered to be a patient-centred approach to health care, ${ }^{1 \mathrm{e} 6}$ and this claim may be used to differentiate the osteopathic profession from other health professions, including medicine. ${ }^{7}$ Some declare that a patient-centred approach is a 'hallmark' of osteopathy ${ }^{8}$; others claim that it is the profession's distinct 'contribution' to the wider system of healthcare. ${ }^{9}$ However, continued reflection by the profession is required in order to have a clear understanding of osteopathy's position in modern day health care. This involves challenging previous assumptions and explicating implicit aspects of practise through research. This article discusses the complex concept of patient-centeredness and critically reflects on whether this approach can be considered a defining feature unique to osteopathy. As the osteopathic profession moves towards a model of practise, informed by research this paper highlights the challenges facing patientcentred osteopathy. 


\section{The emergence of patient-centred care}

A biopsychosocial model of care has spread globally as a result of the dissatisfaction of the conventional 'biomedical model' of care, where patients are reduced to a collection of clinical signs and symptoms, embodying a specific disease taxonomy or diagnosis. ${ }^{10}$ In this latter approach the task of the practitioner is to identify and measure the disease or dysfunction, proceeding to direct treatment to the 'biological' disease. While this essentially positivist model fits well with scientific enquiry and evidence-based medicine, it places the practitioner (and researcher) as a detached and objective individual. This disease-centred approach is also referred to as technique-, method-, therapist-, science-, explanation- or diagnosis-centred. ${ }^{11}$

In the last 40 years there has been a movement away from a disease-centred approach to a biopsychosocial model of healthcare. ${ }^{10,12}$ The biopsychosocial model recognises the complex twoway practitionerepatient relationship, where decisions are shared, and knowledge about 'what to do' is embodied within a relationship. The practical application of this approach is patientcentred care, ${ }^{11}$ and considers the social and psychological aspects of disability as well as the medical or biological dysfunction. ${ }^{13}$ Patientcentred care appreciates the personal meaning of illnesses, pain and suffering in order to understand and help alleviate the disease and dysfunction. Adopting this model means that patients are no longer seen as passive recipients of healthcare but are increasingly seen as active consumers, where their experiences, opinions and perspectives need to be incorporated into clinical reasoning and decision-making. ${ }^{14}$ This transition in healthcare approach has also shifted the patientepractitioner relationship from one which was originally asymmetrical and paternalistic (with the authority laying on the side of the practitioner) to one which is mutual and egalitarian. ${ }^{15}$

\section{Defining patient-centeredness}

Patient-centeredness is often considered a 'fuzzy concept', meaning that while most practitioners will be familiar with the general idea, there are a variety of different interpretations and conceptualisations of it and how it is specifically practised. ${ }^{16}$ There continues to be a lack of a universally agreed definition or conceptualisation of the term, resulting in considerable ambiguity concerning the precise components of a patientcentred approach. ${ }^{16}$ For example, frequently the terms patient-centeredness, patient-centred care, or patient-centred approach are used interchangeably (as will be the case for this current discussion), but what unites the terms is an opposition to a 'one-size fits all' approach to health care provision. ${ }^{17}$ Others prefer the term 'person', and consider that the word 'patient' tends to reduce the individual to a mere passive recipient of healthcare, or to 'one who is acted on'. ${ }^{18}$ Moreover, the term person-centred perhaps recognises more fully, the significance of knowing the person behind the patient $e$ "as a human being with reason, will, feelings, and needs $e$ in order to engage the person as an active partner in his/her care and treatment". ${ }^{18}$ p. ${ }^{249}$ Balint ${ }^{19}$ was perhaps the earliest to coin the term 'patient-centred medicine', describing that each patient "has to be understood as a unique human-being," in contrast to what he termed 'illness-orientated medicine'. ${ }^{19}$ p. ${ }^{269}$ Also from the perspective of medicine, McCormick ${ }^{13}$ states that "knowing the patient who has the disease, is as important knowing the disease which the patient has". ${ }^{20 \text { p. }}{ }^{668}$ A conceptual framework of patient-centeredness is provided by Mead and Power, ${ }^{15}$ who comprehensively describe five distinct characteristics of patient-centeredness, and is shown in Table 1.

A patient-centred approach cannot be applied in the same way for every patient; in doing this the practitioner would be employing an unpatient-centred, patient-centred approach! Take for example a patient who chooses to abdi- cate responsibility in the decision-making process and has no desire to receive information about their treatment. Rather than try and force the reluctant patient to take responsibility and unwanted information, a patient-centred approach might involve discussing each other's expectations and perspectives to aid mutual understanding and negotiation. ${ }^{21}$ In this case, a patient-centred approach does not mean sharing all decisions and all information with all patients. It is the adjustment and flexibility of the practitioner to the individual patient that is at the heart of a patient-centred approach. Paradoxically, this may mean that in some situations it may be patient-centred to take a less patient-centred approach. ${ }^{22}$

\section{Patient-centeredness and the practise of other health professions}

The nursing profession was perhaps the first health profession to declare a patient-centred approach, the origins of which can be traced back to the 
Table 1 Characteristics of patient-centred care with examples of how they might be carried out in osteopathic practise. $^{15}$

\begin{tabular}{|c|c|c|}
\hline Characteristics & Description & Example \\
\hline $\begin{array}{l}\text { Biopsychosocial } \\
\text { perspective }\end{array}$ & $\begin{array}{l}\text { Broadening the explanatory perspective to } \\
\text { include biological, psychological and social } \\
\text { aspects of pain and dysfunction. }\end{array}$ & $\begin{array}{l}\text { The willingness of the osteopath } \\
\text { to understand the social and } \\
\text { emotional impact of chronic } \\
\text { neck pain on a patient, rather } \\
\text { than a purely as a biological } \\
\text { entity. }\end{array}$ \\
\hline $\begin{array}{l}\text { The patient-as- } \\
\text { person }\end{array}$ & $\begin{array}{l}\text { Recognising the individuality of the patient } \\
\text { as a person, thereby placing value on their } \\
\text { personal meaning and interpretation of their illness. }\end{array}$ & $\begin{array}{l}\text { Might include exploring the } \\
\text { patient's narrative during case } \\
\text { history taking, so as to elicit } \\
\text { their expectations, feelings and } \\
\text { fears about an episode of low } \\
\text { back pain. }\end{array}$ \\
\hline $\begin{array}{l}\text { Sharing power } \\
\text { and responsibility }\end{array}$ & $\begin{array}{l}\text { A patientepractitioner relationship which is equal } \\
\text { and symmetrical (rather than paternalistic). Involves } \\
\text { mutual participation, collaboration and negotiation } \\
\text { throughout the episode of care. }\end{array}$ & $\begin{array}{l}\text { May include encouraging the } \\
\text { patient to voice their own ideas } \\
\text { about the cause of their illness } \\
\text { and/or involving them in the } \\
\text { decision-making process during } \\
\text { the development of a longer } \\
\text { term self-care plan. }\end{array}$ \\
\hline $\begin{array}{l}\text { The therapeutic } \\
\text { alliance }\end{array}$ & $\begin{array}{l}\text { A function of the affective bond between patient } \\
\text { and practitioner to optimise the therapeutic potential. }\end{array}$ & $\begin{array}{l}\text { The mutual negotiation of } \\
\text { treatment goals and the } \\
\text { agreement on interventions, } \\
\text { or the recognition that the } \\
\text { 'relationship-effect' of } \\
\text { osteopathy is inseparable } \\
\text { from the bio-physiological } \\
\text { effect. }\end{array}$ \\
\hline $\begin{array}{l}\text { The practitioner- } \\
\text { as-person }\end{array}$ & $\begin{array}{l}\text { Self-awareness of the influence of the personal } \\
\text { qualities of the practitioner and the way that } \\
\text { they practise. }\end{array}$ & $\begin{array}{l}\text { The self-awareness by a } \\
\text { practitioner of their emotions } \\
\text { which might be engendered } \\
\text { by a particular patient } \\
\text { presentation, or the } \\
\text { recognition of the subjectivity } \\
\text { of a diagnostic or therapeutic } \\
\text { technique. }\end{array}$ \\
\hline
\end{tabular}

1850s and Florence Nightingale, who viewed the patient-focused approach of nursing distinct from the disease-orientated approach of the medical profession. ${ }^{23}$ There is a continued effort by the nursing profession ${ }^{18,23}$ and many other health professions to better understand what patientcenteredness means for their practitioners and their patients, including physiotherapy, ${ }^{24 \mathrm{e} 26}$ chiropractic $^{27 e 29}$ and even pharmacy. ${ }^{30 e 32} \mathrm{~A}$ failure to have such an understanding prevents professions from establishing how their practitioners put patient-centeredness into action.

For example, in the physiotherapy profession, characteristics of patient-centeredness were found in 'expert' practitioners ${ }^{33}$ who emphasised their role to guide and educate patients towards their recovery. ${ }^{34}$ They emphasised the need to listen and learn from their patients rather than tell and direct. This research, spanning twelve years described the practise of experienced therapists (compared to novice practitioners) as more socially engaging, whilst still completely focused on the patient and their treatment modality. ${ }^{35}$ Interestingly, these researchers claimed that the experienced practitioners appeared to 'enter the lives' of their patients with a two-way dialogue eliciting and providing information pertaining to the treatment. ${ }^{36}$

During the same period, researchers in other health professions, such as occupational therapy were recognising that their practitioners went beyond only reasoning towards a diagnosis, but they took a 'patient-centred' and individualised approach to patient treatment and management. ${ }^{37,38}$ Occupational therapists tailored their treatment approach to suit the individuality of the 
patient. While these therapists took a traditional scientific approach to diagnosis, they also endeavoured to match the right treatment approach for the right patient and considered the skills, needs and interests of each individual patient. ${ }^{37}$

This understanding of patient-centeredness in other professions leads to a number of questions for osteopathy. Are osteopaths patient-centred and if so, are they patient-centred in the same way as physiotherapists and occupational therapists? Do osteopaths have a unique understanding and approach to patient-centred care that is distinguishable from other health professionals? Is patientcenteredness an attribute found in all levels of osteopathic practise or just in those practitioners with greater expertise and/or experience? With the widespread use of the biopsychosocial model amongst various health professions, all of which claim to take a patient-centred approach to their practise, can a patient-centred approach be a unique defining feature of osteopathy? We have begun to explore the nature of osteopathic clinical reasoning using a grounded theory qualitative research study. ${ }^{14}$ The study is still underway but early findings suggest that osteopaths are flexible in different aspects of their patient approach. They may take a bodycentred, patient-centred, and/or person-centred approach, depending on their relationship with the patient; with each approach demonstrating different characteristics of patient-centeredness. At times responsibility and reasoning are shared with the patient, but at other times clinical reasoning is less collaborative and is informed predominantly by the practitioners own meaning and interpretation of the clinical situation, rather than in consultation with the patient's experiences and perspectives. There are also times when practitioners appear to take a more biomedical, disease-centred approach to their reasoning and practise, and other times the same practitioner might be quite biopsychosocially orientated, appreciating the uniqueness and individuality of the person. These findings begin to suggest that osteopathic patient-centeredness is a relational and dynamic process, and forms a basis for further research.

\section{Researching patient-centeredness}

The multidimensional aspect of patient-centred care, presents a challenge to researchers attempting to understand or measure it. Quantitative research approaches have used self-reported surveys or questionnaires to measure how patients and practitioners perceive patient-centred care, and how it impacts consultation outcomes (health outcomes and patient satisfaction). ${ }^{17,39,40}$ Qualitative research approaches have employed direct observation of clinical encounters, and/or interviews with patients and practitioners to help understand the complex, non-linear and relational aspects of patient-centeredness. ${ }^{41} \mathrm{~A}$ recent doctoral study has attempted to explore the nature of patient-centeredness from the perspective of both patient and physiotherapist. ${ }^{42}$ Other research has sought to establish the direct effect patientcentred care has on the health status of patients (using self-reported questionnaires for change in symptoms severity and secondary heath outcomes) ${ }^{43}$ and blood sugar levels in diabetic patients. ${ }^{44}$ However directly linking patientcenteredness to improved health outcomes is particularly difficult to ascertain. While some research has shown an association between patient autonomy and self-reported mental health status, it failed to identify whether higher levels of perceived autonomy were associated with improved physical health status such as better glycaemic control ${ }^{44,45}$ or increased satisfaction and enablement. ${ }^{40}$ Research in the medical profession has, however, demonstrated that adopting a patient-centred approach results in improved patient heath outcome (less discomfort, less concern, and better mental health) and improved efficacy of care (reduced unnecessary diagnostic tests and referrals). ${ }^{43}$

There are many opportunities to explore patientcenteredness within osteopathy. How is patientcenteredness conceived by practitioners and patients? How patient-centred are the different approaches to osteopathy (for example structural, visceral or cranial approaches)? The findings of the recent OPEn study have provided some encouraging evidence to support the notion of patientcenteredness 'in-action' in osteopathy. ${ }^{46}$ This study, which explored the expectations and experiences of patients, showed that osteopaths took a collaborative approach to reasoning and patients felt that osteopaths were proficient in developing an empathetic therapeutic relationship, which was viewed as important by patients. However, areas classifi as 'weak' included: communicating to patients about the nature of treatment and the expected level of pain or discomfort; the likely after-effects of treatment; information on how to complain; understanding how and when osteopaths communicate with the appropriate wider network of health professionals in their area (GPs etc); and fi, advice on how to prevent the problem recurring. ${ }^{46}$ The results highlighted important aspects of osteopathic patient-centred care to inform practitioners, regulators and osteopathic educational institutions. 


\section{Patient-centeredness and osteopathy}

In the UK, Australia and New Zealand the standards of practise set by the regulator espouse patientcentred care as necessary for competent osteopathic practise. ${ }^{3,4,6}$ The osteopathic tenets ${ }^{47}$ (Table 2 ), in their varying revisions recognise the intimate interaction of the mind, body and spirit in health and disease, and are thought to be wholly consistent with the biopsychosocial model. ${ }^{48}$ However, the ambiguity of these principles makes it difficult to link them with contemporary conceptualisations of patient-centred care, as outlined in Table 1. This issue has been partly addressed by Rogers and colleagues ${ }^{49}$ who have attempted to re-align the osteopathic principles to include elements of the patient-centred care model. However, these 'principles of patient care' are directed towards osteopathic physicians in the United States and therefore do not permit the direct transfer to limited licence osteopaths in other parts of the world.

Within osteopathy there has been no shortage of treatment models, osteopathic manipulative techniques or assessment procedures, which are practised by many different practitioners in many different ways. Globally, the practise of osteopathy has predominately centred on the concept of the somatic dysfunction, which is defined as:

"Impaired or altered function of related components of the somatic (body framework) system: skeletal, arthroidal, and myofascial structures, and related vascular, lymphatic, and neural elements."

Many authors within the field of osteopathy claim that these disturbances may be identified using manual palpation of the body regions ${ }^{51 e 53}$ through

identification of tissue texture, asymmetry, range of motion abnormality and tenderness. ${ }^{54}$ In the field of osteopathy, somatic dysfunction is thought to be amenable to osteopathic manipulative therapy, and osteopaths in the UK and Australia employ a broad spectrum of manual therapy techniques which aim to restore normal function. ${ }^{55 \mathrm{e} 57}$

Table 2 Four major principles of osteopathy. ${ }^{47}$

1. The body is a unit; the person is a unit of body, mind and spirit.

2. The body is capable of self-regulation, self-healing, and health maintenance.

3. Structure and function are reciprocally interrelated.

4. Rational treatment is based upon an understanding of the basic principles of body unity, self-regulation, and the interrelationship of structure and function.
Numerous models and theories have been proposed to explain somatic dysfunction, most of which have little research evidence to support them. ${ }^{54,58 e 60}$ Osteopathic researchers, educators and practitioners have placed great clinical and therapeutic significance on the osteopathic somatic dysfunction 'concept' and the identification and treatment of segmental disturbances to the joints and tissues of the spine; this concept continues to play a strong role in the models of practise for many osteopaths in the UK. ${ }^{57,61}$ It is asserted that a major 'goal' of osteopathic practise is to identify (usually through manual palpation of soft tissues and joint mobility assessment) and treat somatic dysfunction. It is common that osteopaths compare deviations between the affected side and unaffected side of the body, in an attempt to identify the fi s of somatic dysfunction. ${ }^{62}$ However, this can be considered to constitute a biomedical form of assessment, and the process of identifying and correcting somatic dysfunction alone is in effect a reductionist activity. The old osteopathic adage, 'find it, fix it and leave it alone ${ }^{63}$ views the practitioner as a car mechanic, fi ing and fixing the problem, like an engine that won't start. Others have also identified echoes of positivism and reductionism in the writings of A.T Still, ${ }^{64}$ and his emphasis on the scientific 'facts' of the patient and their illness. This suggests a biomedical model of practise with the authoritative practitioner making scientifi discoveries of the passive patient, rather than a mutual relationship where the patient takes an active therapeutic role. Adopting such an approach has significant limitations as it fails to link the local and specific 'scientific findings' in the context of the patients narrative, illness experience and the developing patientepractitioner relation-

ship.65 Furthermore, using terminology such as 'abnormal' during biomedically orientated assessment fails to acknowledge the patients' personal meaning and interpretation of their illness and tends to perpetuate experiences of social exclusion for disabled persons. ${ }^{66}$

Patients suffering with non-specific low back pain (LBP) will report many different 'illness experiences', ${ }^{67}$ and LBP will not be experienced in the same way by two different individuals; for example an athlete might ascribe an entirely different personal meaning to their LBP compared to a unemployed single parent. Both have the diagnosis of non-specific LBP, yet their illness experiences, and story will be quite different. ${ }^{67}$ Patientcentred care is about appreciating the different and unique perspective of patients in order to more fully understand the patient's experience of illness, suffering and pain, and collaboratively developing with the patient a treatment and management 
strategy. Research to inform and enhance osteopathic practise needs to more fully appreciate this complex interaction of physical, psychological and societal factors. ${ }^{68,69}$

\section{Patient-centred care and evidence- informed osteopathy: squaring the circle}

Research that focuses on patient-centred care in osteopathy challenges a move towards evidencebased practise. The randomised controlled trial, designed for a biomedical model of healthcare, sits towards the top of the evidence hierarchy. ${ }^{70}$ It assumes homogeneity of patients, failing to recognise the individuality of the patient and their illness experience. It thus generates knowledge that helps inform the biomedical aspects of osteopathic practise but ignores the psychological and social aspects of health and the influence of the patientepractitioner relationship. If the professional knowledge of osteopathic practise is to grow and develop and enhance clinical practise it needs to embrace both quantitative and qualitative research paradigms so that all aspects of practise can be explored. ${ }^{68,71,72}$ This will help to develop an epistemology of osteopathic practise, i.e. an understanding of how osteopaths know what they know and the type of knowledge they use in professional practise. ${ }^{73}$ However challenging and difficult the task, osteopathic researchers must address the bio-, psycho- and social aspects of patient-centred care if they are to succeed in enhancing osteopathic practise to optimise patient care and treatment outcomes.

Finally, both patient-centred care and evidencebased practise have strongly influenced healthcare in the UK during the last 30 years, and both concepts are considered valuable and necessary. ${ }^{16}$ However, how patient-centred can a model of evidencebased osteopathy ever be? How will the profession and its members bridge the gap between the two separate paradigms? Overcoming these challenges, and others, requires a robust research approach and a critically reflective profession.

\section{Conclusion}

The concept of patient-centred care has been discussed in this article, and the complexity and ambiguity of the concept is evidenced by the confounding research in the area. Modern day osteopathy claims a patient-centred approach to healthcare yet it is unknown how this is acted out in practise or how it relates to patient outcomes.
Furthermore, a patient-centred approach embedded within a biopsychosocial model of healthcare is now incorporated into a number of health professions teachings and practises, and these professions are making significant strides in exploring how patient-centred care relates to their practise, practitioners and patients. It is therefore difficult to see how the concept of patient-centred care is able to differentiate osteopathy from other similar health professions. Osteopathy must consider its epistemology of practise in light of contemporary research and a dynamic changing healthcare landscape. This will facilitate an approach to practise which is patient-centred and evidence-informed. Continued research is necessary to help understand the concept of patientcenteredness in the context of contemporary, modern day osteopathy.

\section{Acknowledgements}

Thanks to the British College of Osteopathic Medicine, the British Naturopathic and Osteopathic Association and the Osteopathic Educational Foundation for their support of Oliver Thomson's Doctoral research. Thanks to Mr Phil Austin for his helpful comments.

\section{References}

1. World Health Organisation. Benchmarks for training in osteopathy. Geneva: World Health Organization; 2010.

2. GOsC. What is osteopathy?. Available from: http://www. osteopathy.org.uk/resources/press-office/faqs/\#faq45; 2010.

3. Osteopathy Board of Australia. Osteopathy code of conduct. Available from: http://www.osteopathyboard. gov.au/Codes-Guidelines.aspx; 2011.

4. The Osteopathic Council of New Zealand. Capabilities for osteopathic practice. Available from: http://www. osteopathiccouncil.org.nz/competency-standards.html; 2010.

5. Butler R. The patient encounter: patient-centered model. In: Chila A, Fitzgerald M, editors. Foundations of osteopathic medicine. Lippincott Williams \& Wilkins; 2010. p. 371 e6.

6. GOsC. Osteopathic practice standards. London: General Osteopathic Council; 2011.

7. Howell JD. The paradox of osteopathy. N Engl J Med 1999; 341:1465e8. 
8. Bates B. Overview of the osteopathic medical model: osteopathic education and regulation. In: Chila A Fitzgerald $M$, editors. Foundations of osteopathic medicine. Lippincott Williams \& Wilkins; 2010. p. 3e46.

9. Stone C. Placing osteopathy in relation to healthcare philosophies and systems. In: Stone C, editor. Science in the art of osteopathy: osteopathic principles and practice. Cheltenham: Stanley Thornes; 1999. p. 1 e14.

10. Engel GL. The need for a new medical model: a challenge for biomedicine. Science 1977;196:129.

11. Langendoen J. The patient-centredness of evidence-based practice. A case example to discuss the clinical application of the bio-psychosocial model. Man Ther 2004;9:228.

12. Engel GL. The clinical application of the biopsychosocial model. Am J Psychiatry 1980.

13. World Health Organisation. International classification of functioning, disability and health. Geneva: World Health Organization; 2001.

14. Thomson OP, Petty NJ, Moore AP. Clinical reasoning in osteopathy e more than just principles? Int J Osteopath Med 2011;14:71e6.

15. Mead N, Bower P. Patient-centredness: a conceptual framework and review of the empirical literature. Soc Sci Med 2000;51:1087e110.

16. Bensing J. Bridging the gap: the separate worlds of evidence-based medicine and patient-centered medicine. Patient Educ Couns 2000;39:17e25.

17. Epstein RM, Franks P, Fiscella K, Shields CG, Meldrum SC, Kravitz RL, et al. Measuring patient-centered communication in patientephysician consultations: theoretical and practical issues. Soc Sci Med 2005;61:1516e28.

18. Ekman I, Swedberg K, Taft C, Lindseth A, Norberg A, Brink E, et al. Person-centered care e ready for prime time. Eur J Cardiovasc Nurs 2011;10:248e51.

19. Balint $\mathrm{E}$. The possibilities of patient-centered medicine. $J R$ Coll Gen Pract 1969;17:269.

20. McCormick J. Death of the personal doctor. Lancet 1996; 348:667.

21. Jones M, Edwards I, Gifford L. Conceptual models for implementing biopsychosocial theory in clinical practice. Man Ther 2002;7:2e9.

22. Zandbelt LC, Smets EMA, Oort FJ, Godfried MH, de Haes HCJM. Determinants of physicians' patient-centred behaviour in the medical specialist encounter. Soc Sci Med 2006;63:899e910.

23. Lauver DR, Ward SE, Heidrich SM, Keller ML, Bowers BJ, Brennan PF, et al. Patient-centered interventions. Res Nurs Health 2002;25:246e55.

24. Hall AM, Ferreira PH, Maher CG, Latimer J, Ferreira ML. The influence of the therapistepatient relationship on treatment outcome in physical rehabilitation: a systematic review. Phys Ther 2010;90:1099e110.

25. Kidd $\mathrm{MO}$, Bond $\mathrm{CH}$, Bell ML. Patients' perspectives of patient-centredness as important in musculoskeletal physiotherapy interactions: a qualitative study. Physiother 2011;97:154e62.

26. Randall KE, MCEwen IR. Writing patient-centered functional goals. Phys Ther 2000;80:1197e203.

27. Gatterman MI. A patient-centered paradigm: a model for chiropractic education and research. J Altern Complement Med 1995;1:371e86.

28. Jamison JR. Reflections on chiropractic's patient-centered care. J Manipulative Physiol Ther 2001;24:483e6.

29. Miller PJ, Gemmell HA. Patient centred care in chiropractic practice. Clin Chiropract 2004;7:141e6.

30. Al-Shaqha WMS, Zairi M. Pharmaceutical care management: a modern approach to providing seamless and integrated health care. Int J Health Care Qual Assur 2001; 14:282e301.

31. Strand L, Guerrero R, Nickman N, Morley P. Integrated patient-specific model of pharmacy practice. Am J HealthSystem Phar 1990;47:550e4.

32. Clifford S, Barber N, Elliott R, Hartley E, Horne R. Patientcentred advice is effective in improving adherence to medicines. Pharm World Sci 2006;28:165e70.

33. Jensen GM, Gwyer J, Shepard KF. Expert practice in phys ical therapy. Phys Ther 2000;80:28e43. discussion 44e52.

34. Jensen GM, Shepard KF. Expertise in physical therapy practice. Saunders Elsevier; 2006.

35. Jensen GM, Shepard KF, Gwyer J, Hack LM. Attribute dimensions that distinguish master and novice physical therapy clinicians in orthopedic settings. Phys Ther 1992; 72:711e22.

36. Jensen GM, Shepard KF, Hack LM. The novice versus the experienced clinician: insights into the work of the physical therapist. Phys Ther 1990;70:314e23.

37. Fleming $\mathrm{MH}$. Clinical reasoning in medicine compared with clinical reasoning in occupational therapy. Am J Occup Ther 1991a;45:988e96.

38. Mattingly C, Fleming MH. Clinical reasoning: forms of inquiry in a therapeutic practice. Philadelphia: F.A. Davis; 1994.

39. Little P, Everitt H, Williamson I, Warner G, Moore M, Gould $C$, et al. Preferences of patients for patient centred approach to consultation in primary care: observational study. BMJ 2001;322:468.

40. Mead N, Bower P, Hann M. The impact of general practitioners' patient-centredness on patients' post-consultation satisfaction and enablement. Soc Sci Med 2002;55:283e99.

41. Griffiths F, Borkan J, Byrne D, Crabtree BF, Dowrick C, Gunn J, et al. Developing evidence for how to tailor medical interventions for the individual patient. Qual Health Res 2010;20:1629e41.

42. Sexton M. Patient-centred care: an exploration of its meaning for musculoskeletal physiotherapists and patients with low back pain. University of Brighton 2011; unpublished doctoral thesis.

43. Stewart M, Brown J, Donner A, McWhinney I, Oates J, Weston W, et al. The impact of patient-centered care on outcomes. J Fam Pract 2000;49:796.

44. Lee $\mathrm{Y}-\mathrm{Y}$, Lin JL. Do patient autonomy preferences matter? Linking patient-centered care to patientephysician relationships and health outcomes. Soc Sci Med 2010;71: 1811 e8.

45. Kinmonth AL, Woodcock A, Griffin S, Spiegal N, Campbell MJ. Randomised controlled trial of patient centred care of diabetes in general practice: impact on current wellbeing and future disease risk. BMJ 1998;317:1202e8.

46. Leach J, Cross V, Fawkes C, Mandy A, Hankins M, Fiske A, et al. Investigating osteopathic patients' expectations of osteopathic care: the OPEn project 2011.

47. Special Committee on Osteopathic Principles and Osteopathic Technique by Kirksville College of Osteopathy and Surgery. The osteopathic concept. An interpretation. J Osteopathy 1953;60:7e10.

48. Penney NJ. The biopsychosocial model of pain and contemporary osteopathic practice. Int J Osteopath Med 2010;13:42e7.

49. Rogers F, D'Alonzo Jr G, Glover J, Korr I, Osborn G, Patterson $\mathrm{M}$, et al. Proposed tenets of osteopathic medicine and principles for patient care. J Am Osteopath Assoc 2002; 102:63e5.

50. Educational Council on Osteopathic Principles of the American Association of Colleges of Osteopathic Medicine. Glossary of osteopathic terminology. In: Ward R, editor. 
Foundations for osteopathic medicine. 2nd ed.. Philadelphia: Lippincott Williams \& Wilkins; 2003. p. 1229e53.

51. DiGiovanna EL, Schiowitz S. An osteopathic approach to diagnosis and treatment. 2nd ed. Philadelphia: LippincottRaven; 1997.

52. Greenman PE. Principles of manual medicine. 3rd ed. Philadelphia, PA/London: Lippincott Williams \& Wilkins; 2003.

53. Kappler RE. Palpatory skills and exercises for developing the sense of touch. In: Ward RC, editor. Foundations for osteopathic medicine. 2nd ed.. Philadelphia: Lippincott Williams \& Wilkins; 2003. p. 557e65.

54. Fryer G. Intervertebral dysfunction: a discussion of the manipulable spinal lesion. J Osteopath Med 2003;6:64e73.

55. GOsC. General osteopathic council survey and statistics. Available from: http://www.osteopathy.org.uk/uploads/ survey2snapshot_survery_results_2001.pdf; 2001.

56. Orrock PJ. Profile of members of the Australian Osteopathic Association: Part 2 e the patients. Int J Osteopath Med 2009;12:128e39.

57. Fryer G, Johnson JC, Fossum C. The use of spinal and sacroiliac joint procedures within the British osteopathic profession. Part 2: Treatment. Int J Osteopath Med 2010.

58. Van Buskirk R. Nociceptive reflexes and the somatic dysfunction: a model. J Am Osteopath Assoc 1990;90:792.

59. Korr I. The neural basis of the osteopathic lesion. J Am Osteopath Assoc 1947;47:191e98. In: Peterson B, editor. The collected papers of Irvin M. Korr. Indianapolis: American Academy of Osteopathy; 1979. p. 120 e7.

60. Fryer G. Somatic dysfunction: updating the concept. Aust J Osteopath 1999;10:14e9.

61. Fryer G, Johnson JC, Fossum C. The use of spinal and sacroiliac joint procedures within the British osteopathic profession. Part 1: Assessment. Int J Osteopath Med 2010.
62. Sammut EA, Searle-Barnes PJ. Osteopathic diagnosis. Cheltenham: Stanley Thornes; 1998.

63. Still AT. Philosophy of osteopathy 1899 . Kirksville.

64. Lucas NP, Moran RW. Is there a place for science in the definition of osteopathy? Int J Osteopath Med 2007;10: $85 \mathrm{e}$.

65. Thornquist E. Diagnostics in physiotherapy e processes, patterns and perspectives. Part II. Adv Physiother 2001;3: 151 e62.

66. Edwards I, Richardson B. Clinical reasoning and population health: decision making for an emerging paradigm of health care. Physiother Theory Pract 2008;24:183e93.

67. Corbett M, Foster NE, Ong BN. Living with low back pain e stories of hope and despair. Soc Sci Med 2007;65:1584e94.

68. Thomson OP, Petty NJ, Ramage CM, Moore AP. Qualitative research: exploring the multiple perspectives of osteopathy. Int J Osteopath Med 2011;14:116e24.

69. Foster N, Pincus T, Underwood M, Vogel S, Breen A, Harding G. Understanding the process of care for musculoskeletal conditions $\mathrm{e}$ why a biomedical approach is inadequate. Rheumatology 2003;42:401.

70. Sackett DL. Evidence-based medicine: how to practice and teach EBM. 2nd ed. Edinburgh: Churchill Livingstone; 2000.

71. Petty NJ, Thomson OP, Stew G. Ready for a paradigm shift? Part 1: introducing the philosophy of qualitative research. Man Therapy, in press.

72. Petty NJ, Thomson OP, Stew G. Ready for a paradigm shift? Part 2: introducing qualitative research methodologies and methods. Man Therapy, in press.

73. Richardson B, Higgs J, Dahlgren MA. Recognisng practice epistemology in the health professions. In: Higgs J, Richardson B, Dahlgren MA, editors. Developing practice knowledge for health professionals. Edinburgh: Butterworth Heinemann; 2004. p. 1e14. 